\title{
The Factors Influencing on low Demand for Travel to Iran
}

\author{
Maysam Musai \\ Professor, University of Tehran, Tehran,Iran \\ E-mail:mousaaei@ut.ac.ir \\ Mohsen Mehrara \\ Professor, University of Tehran, Tehran,Iran \\ Hamid Reza Ashrafzadeh \\ Institute for Trade Studies and Research, Tehran, Iran \\ Fateme Nemati \\ M.A in Tourism Planning, University of Tehran \\ Fereshteh Barati \\ M.A in Economics, University of Tehran \\ Zahra Aghajani \\ Institute for Trade Studies and Research, Tehran, Iran
}

DOI: $\quad$ 10.6007/IJARBSS/v4-i3/741 URL: http://dx.doi.org/10.6007/IJARBSS/v4-i3/741

\begin{abstract}
Factors having an influence on travel demand to Iran are explored. The hypothesis specifies the variable of "domestic upheavals and insecurity" as the most significant obstacle to expansion of the demand for travel to Iran.

Several demand models are briefly reviewed, and then in a macro model the function of demand for travel to Iran is estimated, using econometric methods. The substantial finding is at the moment, the low demand for travel to Iran is not due to insufficient infrastructures and facilities, but it is because of the element of "insecurity". Hence, this issue needs to be addressed by new policies.
\end{abstract}

Keyword: Tourism, Economics of Tourism, Travel demand, Iran 


\section{Introduction}

At the present time, the tourism industry has developed extensively worldwide, and through which many countries have been able to improve their own conditions substantially, whilst overcoming some of their economic problems including low per capita income, high unemployment and insufficient foreign exchange revenues. Thus, at the present time, the tourism industry revenue constitutes almost 6\% of total global exports (Sabagh Kermany 1997). This figure amounts to over 444 billion dollars and, is equal to $35 \%$ of the total global service export (Musai, 2000:3). The foreign exchange revenue from the tourism industry is increasing on a continuous basis, such that it has increased four folds when compared to the 1960's (Musai, 2000).

Our country, despite its diverse ecosystems on the one hand, and being in possession of a unique collection of historical and cultural sites on the other, is among the few countries that have not turned their potential capacities in this area into positive advantage. A review of the tourism industry in Iran, and considering its foreign exchange revenue potential, illustrates that in spite of the fact that Iran ranks among the top ten countries having the most distinguished historical and ancient sites, it earns less than a thousandth of the global tourism revenue. Moreover, considering the over-dependence of the Iranian economy on the export of crude oil and its extreme vulnerability in face of oil price fluctuations and other economic and noneconomic shocks, the development of tourism industry could reduce this vulnerability significantly. It would also help economic policy makers to overcome the current problems such as low foreign exchange revenue, low level of income in the society, low level of non-oil export and unemployment.

\section{A Review of Literature on Demand for Tourism}

Economic studies in the field of tourism in Iran are very limited. The most recent study, "A Survey of Tourism Circumstances and an Estimation of Distribution of Demand and Supply of International Tourism in Iran" was sponsored by the "Center for Fundamental Research" and carried out by. Majid Sabagh-e Kermani. In this research he used the available data for the international tourists visiting Iran, up to 1994, (differentiated by the county of origin) to introduce a constant functional format considering the demand for tourism for each country(Sabagh-e Kermani 1997).

There are other studies, which have usually focused on other aspects of the field, such as: "the significance of tourism"(Sociology and Tourism 1994), "the principles of tourism" (Alvani, Dehdashti 1995), "planning for tourism industry" (Ershadi 1996), "economic development"

(Peeran 1993), "sociological aspects of tourism" (Sociology and Tourism 1994), “ and "conditions of tourism in Iran as compared to other countries" (Fayz-Bakhsh 1997).

These research works are usually descriptive and have not offered any model/models to estimate demand or supply functions for tourism. Furthermore, the available tourism-related research about other countries are so extensive that it is beyond the scope of this paper to 
even list the titles. Therefore, in this paper, the research has concentrated on the estimation of functions of demand and supply models categorized according to the type of modeling.

\section{1- Linear Planning Models}

"Van Derkinjff" and "John OosterHoven" published one of the most distinguished applied models for planning demand for tourism (Van Derkinjff, John OosterHoven 1995). This study focuses on tourism in Vaden Islands, which includes 4 islands favored by the German visitors. The main characteristic of these islands is their strong dependence on tourism activities, such that $70 \%$ of the employment activities -either directly or indirectly- depend on tourism. This model is subjected to three provisions and one objective function. The objective function is to maximize the level of employment linked to the number of beds, the number of visiting nights, the employment creation effects of each bed, and the number of new beds, ... and the provisions include the public budget for tourism policies, capacities at different classes of accommodations (different cost levels) and the minimum level of employment rate.

The major objection to these models is that their provisions, which are usually expressed as linear, do not illustrate an acceptable depiction of the reality. Also, the application of these models for developing countries are subject to some hesitation, as utilization of such models requires the "input-output" tables of different sectors including tourism such that the very existence and calculations of such tables in developing countries face great difficulties.

\section{2- Abstract Models}

These models are methods for prediction of travel demand. They estimate and predict the demand using single equations by applying econometric methods. The principles of this model are designed for transportation means and the related demand. The main assumption of the model is that demand for travel by any means of commuting is interrelated with the characteristics of the transportation means and also the environment in which people live. The dependent variable in this model -that is estimated for England-is the number of international trips taken by British citizens. The independent variables are generally a product of multiplication of the population at the point of origin by that of the point of destination and the average weighted income per capita in both points (Will, 1980).

\section{3- Microeconomic Models}

In this category, the theoretical foundations of the models and the concept of "utility" are considered. However, except for the work done by "Lancaster" who offered a new method for utility theory, and also the empirical and statistical estimations presented by "Rugg" in 1973, there has not been any new study.

This model could be summarized as follows:
Objective function
Max: $u_{r}\left(\mathbf{q}_{r} \bar{t}_{r j}\right)$

$$
\text { St: } \bar{t}_{r j} \leq \mathrm{T}_{r}-\bar{t}_{r j} \text { and p.q }{ }_{r}+\mathrm{C}_{j} \bar{t}_{r j}+\mathrm{f}_{r j} \leq \mathrm{Y}_{r}
$$


In which:

$\mathrm{u}_{r}$ : The utility of the tour for the tourist $r$,

$\mathrm{t}$ : The commuting time (round trip),

$\mathrm{f}$ : The tour ticket price,

c: The cost of the trip, per time unit,

$\mathrm{p}$ : The column resultant of the price of other commodities,

$\mathrm{q}$ : The consumption of the other commodities,

$\mathrm{T}$ : The duration of the trip (ex. the number of annual vacation days of the tourist $r$,

$\bar{t}_{r j}$ : The time spent at the destination, by tourist $r$, at the tour $\mathrm{j}$

$\mathrm{j}$ : The number of the tour destinations for the tourist $r$.

The above model has been revised many times, but it has not been estimated empirically.

There are other empirical models in microeconomics that have reached some conclusions, using practical estimations, among which one could refer to "Sakai Model" that is about business trips (Sakai 1988).

Among other models designed with microeconomics tendency and logarithmic functions of demand, which have used the method of utility function (Translog), are models set by "Bokkal" and "Scoperloud", pertaining to the factors affecting demand for tourism in the United States (Bokkal and Scoperloud 1992).

4- "Diamond's" Demand Model

This model was proposed by "Diamond", in an essay titled "The Role of Tourism in Economic Development" to study the demand for tourism in Turkey (Diamond 1971). The original model is formulated as:

$\mathrm{T}={ }_{a} \mathrm{p}^{b 1} \mathrm{Y}^{b 2} \mathrm{~F}^{b 3}$

In which:

$\mathrm{T}$ : The number of the tourists visiting Turkey,

$P$ : The Population of the country of the origin,

Y: Per capita GDP of the country sending the tourist,

F: The air ticket between Istanbul and the capital city of the sender country.

\section{5- “Kilman" Demand Model}

This model is a mono equation and explores the exploitation of time series or cross time data (Panel Data), to perform a quantitative analysis of the Canadian tourism arrivals (Kilman 1981). In this model, the dependent variable is the number of tourist arrivals, and the explanatory variables are inflation indices, the adjusted exchange rate, the price of airplane ticket, and the revenue earned from national and native attractions.

\section{6- "Quondt \& Baumol" Demand Model}

This model explains the collective demand between points $A$ and $B$ as a function of costs of using different means of transportation and other services at the points of origin and destination. In this model, the only means of transportation is the airplane, and the dependent 
variable is the number of trips taken by Canadian citizens to the country of $\mathrm{j}$ at the year $\mathrm{t}$ (Quondt \& Baumol 1970).

\section{7- "Arbel \& Abraham" Demand Model}

The quantity of the tourists demand for NY State Parks is estimated, and different variables such as ecosystem, fuel cost, fuel deficiency, the value of dollar against other foreign exchange have been considered (Arbel \& Abraham 1985).

The model is formulated as:

$\operatorname{LnQ}_{D}=\mathrm{b}_{0}+\mathrm{b}_{1} \ln { }_{Y}+\mathrm{b}_{2} \ln \mathrm{p}_{E}+\mathrm{b}_{3} \ln \mathrm{T}+\mathrm{b}_{4} \mathrm{~A}+\mathrm{b}_{5} \ln \mathrm{H}$

In which:

T: Real cost of transportation,

A: A dummy variable for fuel deficiencies,

$\mathrm{H}$ : The price index for accommodations,

$\mathrm{Q}_{D}$ : The number of visits to the park,

$\mathrm{Y}$ : The definable real revenue,

$\mathrm{p}_{E}$ : The gas price,

W: The ecosystem index,

$X$ : The foreign exchange variable.

The findings of the model show that, with no doubts, the elasticity of income is the strongest factor that indicates the scale of recreational activities.

The main objection to the model is that it would not be used in comparative studies, between countries, or that it may not be applicable to international tourism. Nevertheless, the main structure of the model with some modifications could be exploited to design a function for international demand for tourism.

\section{8- Truett \& Truett Model}

In this model, the formulation for the tourism demand is:

$\mathrm{Q}_{\mathrm{j}}=\mathrm{AY}^{B 1} \mathrm{P}_{i}^{B 2} \mathrm{X}_{i}^{B 3}$

$Q_{i}$ : Demand for tourism in the country $i$,

A : Constant coefficient,

$Y$ : Real incomes of the visitors,

$P_{i}$ : The ratio of the real indices of the prices in the country $I$,

$X_{i}$ : The ratio of the foreign exchange indices of the country $i$.

Truett and Truett have estimated this model and the findings have shown that the variable of exchange rate and the variable of the prices have a linear correlation and except for the variable of the of exchange rate, almost all other variables are meaningful at the $5 \%$ level (Truett, Truett 1987). 


\section{9- "Uysal \& Crompton" Model}

In this mono equation model the factors affecting demand for flow of tourism to turkey is studied (Uysal, Crompton 1984). The number of tourists is the dependent variable, and the explanatory and independent variables are: the Gross Domestic Product, the population of the tourist's country of origin, the consumer price index in the tourist's country of origin, the consumer price index in Turkey, exchange rate for Turkey's currency, and the sum total of expenses of tourism.

\section{0- Other Experimental Models of Demand for Tourism}

Among other studies on demand for tourism in developing countries, one could mention the research works done by "Summary" (Summary 1987). These two models are formulated as:

$\mathrm{X}={ }_{a} \mathrm{Y}^{b 1} \mathrm{~A}^{b 2} \mathrm{E}^{b 3} \mathrm{P}^{b 4}$

$\mathrm{X}={ }_{a} \mathrm{Y}^{b 1} \mathrm{~A}^{b 2} \mathrm{E}^{b 3} \mathrm{P}^{b 4} \mathrm{e}^{b 4} \mathrm{TAN}$

The first model is developed to estimate the number of tourists that travel to only one country, and the second is to estimate the number of tourists that, usually, travel to several countries.

In this formula:

$X$ indicates the number of tourists,

$Y$ stands for the disposable income in the country of origin,

A stands for the ticket price, adjusted for inflation rate,

E stands for the exchange rate for Kenyan currency,

$P$ is the variable for the relative price, which is obtained by dividing the index of consumer prices in the tourist's country origin to the index of consumer prices in Kenya,

TAN is a dummy variable that indicates the effects of closing Tanzanian borders.

The main problem of these models is due to the co-linearity of the models, which is left unsolved.

The above material is a brief survey of the relevant literature but as it was stated earlier, so far only one research has been carried out about demand for flow of tourism to Iran. This research has used the data and statistics of several countries that had sent tourists to Iran during the years prior to 1994. The data has been used to calculate the demand for tourism, differentiated by the country of origin.

The present essay utilizes the most recent available data and statistics using a model that is introduced for this purpose to estimate the sum total of the international demand for tourism in Iran.

\section{Factors Affecting International Demand for Tourism in Iran}

In this section, we introduce and estimate a function of demand for tourism in Iran and explore the degree of influence of effective variables on demand for international tourism in Iran.

It should be stated that this model has been proposed considering statistical limitations in some fields of tourism in Iran, and also, it is done after introducing other models of demand. The available data are used to maximum potentials. Furthermore, it has a high capability to explain. The main thesis is that the major obstacles to growth of demand for tourism in Iran are 
cultural issues and a feeling of insecurity. Hence, the economic issues and local facilities, and capacities, considering the present level of tourism industry in Iran, have little significance.

\section{Function of Demand for Tourism}

In this section, in order to estimate the demand function, the time series data for the period 1970 to 2002 have been utilized.

The general format of the function for tourism demand which is estimated in this study is:

$\log \mathrm{Y}_{t}=\mathrm{a}_{0}+\mathrm{a}_{1} \log \left(\mathrm{X}_{1 t}\right)+\mathrm{a}_{2} \log \mathrm{X}_{2 t}+\mathrm{a}_{3} \log \left(\mathrm{Y}_{t-1}\right) \mathrm{a}_{4} \mathrm{Dum}+\mathrm{U}_{t}$

In which:

$\mathrm{Y}_{t}$ : The revenue (dollars) from tourism as dependable variable,

$\mathrm{X}_{1 t}$ : The ratio of domestic consumer price index to the global consumer price index, as the price variable,

$\mathrm{X}_{2 t}$ : World "Gross Domestic Product" (in dollars), as the scale variable (revenue variable),

$\mathrm{Y}_{t-1}$ : Tourism revenue in the previous period,

DUM : Dummy variables to consider political and social issues and the war during the past 20 years,

$\mathrm{U}_{t}$ : The residual component

According to the demand theory in economics, it is anticipated that:

$a 1<0$

a $2>0$

a3 $>0$

To calculate the above equation, the following variables are defined and substituted:

TRREV: Foreign exchange revenue from tourism, instead of variable $\mathrm{Y}_{t}$

$\frac{C P I}{C P I W}$ : The ratio of the consumer price index in Iran to the global consumer price index, instead of $X_{1 t}(1369=1990=100)$,

\$GDPworld: Global gross domestic products (dollars), instead of the variable $\mathrm{X}_{2 t}$,

TRREV(-1) : Foreign exchange revenue earned from tourism during the previous period, instead of variable $Y_{t-1}$,

DUM78: Dummy variable to consider the impacts of the first year of the Islamic Revolution, DUM7987: Dummy variable to consider the impacts of the war.

Including these variables and considering the resultant of the introduced equation, and also elimination of the auto-correlations from the residual components of the equation, using the models of "Moving Average" (MA) and "Auto Regressive" (AR), the following final results were obtained: 
$\log ($ TRREV $)=3.11-0.252 \log \left(\frac{C P I}{C P I W}\right)+0.45 \log (\$ G D P$ world $)+0.9 \operatorname{logTRREV}(-1)-1.4 \mathrm{DUM78}-$

$0.5 \mathrm{DUM} 7987$

$\begin{array}{lllcccc}\text { SE: } & 1.07 & 0.05 & 0.09 & 0.04 & 0.12 & 0.01 \\ \mathrm{t}: & (-2.9) & (-4.24) & (-4.66) & (53.86) & (-10.95) & (-36.77)\end{array}$

$\mathrm{R}^{2}=0.992$

$\mathrm{F}=240.47$

h-Durbin $=0.4$

As stated earlier, the dummy variables DUM78 and DUM79-87 are included in the equation. Concerning then DUM78, it should be explained that following the Islamic Revolution, due to new social and political circumstances, the number of attracted tourists and the related tourism revenue were reduced substantially. Therefore, in this regard a dummy variable is to be accounted for. This variable for the year 1358 (1978-79) is taken as equal to one and for the remaining years it is taken equal to Zero.

Also, throughout the period of the war, we observed a decrease in foreign exchange revenue from tourism and so the Dum7987 is included in the equation. For the war years, DUM7987 is taken equal to 1 and for the peacetime it is taken equal to zero.

The two dummy variables are considered as substitute variables and indices for the assessment of the effects of security and the feeling of security upon demand for travel to Iran. After the victory of the revolution, and through out the war period the circumstances in the country were not normal, hence the state of security in this period when compared to the pre-revolution era and also in the years after the war had diminished; according to this hypothesis, there was a negative impact on international demand for tourism in Iran.

The interpretation of the findings from estimation of the equation is:

A- All the coefficients have the anticipated algebraic sign and are in agreement with the hypothesis.

B- All the coefficients of the descriptive variables are statistically significant and (Student's $t$ statistic for each coefficient is meaningful).

C- Statistic $\mathrm{R}^{2}$ indicates that explanatory variables that are included in the equation, explain 0.992 of the fluctuations of the dependent variable, and this verifies the explanatory abilities of the equation.

D- Statistic F indicates that the total Regression is meaningful.

$\mathrm{E}$ - Since, there is a delayed dependent variable at the right side of the estimation equation, the statistician Durbin Watson (D.W.) cannot be used and it is necessary to use the statistic h-Durbin. 'Since the statistic $h$-Durbin in this equation is equal to 0.40 and that means, $-1.96<\mathrm{h} . \mathrm{D}<1.96$, the assumption of an auto-correlation among the residual components is rejected. As mentioned earlier, in order to eliminate the serial correlations among the residual components, the models " $A R$ " and " $M A$ " have been applied. 
F- The Coefficient $a_{1}=-0.252$ indicates a $1 \%$ increase in the ratio of $\frac{C P I}{C P I W}$ (the index for consumer price in Iran over that of the global level) reduces the demand for tourism by $0.25 \%$. In other words, if the prices of commodities and consumer services in Iran increase at a faster pace than those of a global scale, the demand for international tourism in Iran will decrease. However, it could be said that the international demand for travel to Iran is not very sensitive to the fluctuations of $\frac{C P I}{C P I W}$ and the function of demand for tourism, in relations to the cost has a low elasticity.

VII-The coefficient of $\mathrm{a}_{2}=0.45$ indicates that $1 \%$ increase in global sum of Gross Domestic Product, (or the increase in the level of income of the international tourists) increases the demand for tourism by $0.45 \%$. In other words, the elasticity of the income function for the flow of international tourism to Iran is equal to 0.45 . Since this elasticity of income is between zero and one, traveling to Iran from the viewpoint of foreign tourists is ranked as a "necessity" and not a "luxury". Hence, the demand to travel to Iran, in proportion to the income variation of the foreign tourist has a low elasticity.

VIII- The coefficients of dummy variables (particularly those of the revolution and war) imply the strong sensitivity of tourism industry to social and political issues. They indicate that despite a rich historical and ancient background and potential capacities of the country, the social, and political and security issues and events have left the tourism industry in Iran with some critical problems.

Since the above function has a logarithmic format, the coefficients of the independent variables, which are also logarithmic, express the sensitivity and elasticity of the related independent variable. On this basis, the following conclusions can be obtained:

i. Elasticity of the foreign exchange revenue from tourism in proportion to the ratio of domestic index of consumer prices to the global index of the consumer prices is equal to -0.25 . It means that for every one percent domestic price increase in comparison with global prices, the foreign exchange revenue decreases by 0.25 percent. In other words, the foreign exchange revenue from tourism in relation to the domestic prices has a low level of elasticity. The reason for this is a high degree of difference between domestic prices and those of the international market. Hence, the level of domestic prices is not a significant factor to attract the tourists.

ii. The elasticity of foreign exchange revenue earned from tourism as a ratio of the level of global revenue (Global Gross Domestic Product) is only 0.45 . This is a positive elasticity. This is also in accord with the hypothesis, because as the level of global product increases, the level of demand for traveling to the country increases. According to this coefficient, for every "one percent" 
increase in the level of total world "Gross Domestic Product", there is a $0.45 \%$ increase in the demand to enter the country and vice versa.

iii. The elasticity of the foreign exchange revenue from the tourism industry in Iran, for each year, in comparison with the revenue from tourism in the previous year is 0.9. It means for each extra dollar added to the dollar revenue earned from tourism each year, there would be an extra 0.9 dollar in the following year.

iv. The foreign exchange revenue earned from tourism industry is highly vulnerable in regard to security issues. Two concepts that could be substituted for the security as substitute variables are:

i) The occurrence of the war during the years 1979- 1987;

ii) The triumph of the Islamic Revolution in 1979.

The first factor shown with the Dum7987 has a coefficient of -0.5 , and the amount of which indicates that the war had a negative impact on the foreign exchange revenues. In other words the impact of the war is estimated to be as much as -0.5 on the Logarithm of each unit of foreign exchange revenue.

The coefficient of dummy variable of occurrence of the revolution is equal to 1.38, which indicates a very deep impact indeed upon the foreign exchange revenues earned from tourism in Iran.

Since the dependent variable is logarithmic but dummy variables are not, the estimated coefficients of the dummy variables, unlike other coefficients, do not show the degree of elasticity. To calculate the relative variation of the dependent variable, due to the impacts of the dummy variables of the war and the revolution, one could apply the methods of "Robert Halvorson and "Raymond Packmosit."

For this purpose the antilogarithm of the coefficients of the dummy variables are estimated (on the basis of e). Then, the resultant is deducted by 1 . If this is done correctly, the relative variation of the foreign exchange revenue as a consequence of the variable of the revolution is -0.75 ; and the consequence of variable of the war equals to -0.39 . These figures are not only large and considerable, but also they illustrate the significance of security as a factor influencing the demand for tourism. In other words, since at the present time the level of demand to travel to Iran is very low, raising the capacity of accommodations services and recreational facilities, etc. in order to raise the level of demand for travel to Iran would be an exercise in futility.

\section{Conclusions}

The study reaches the conclusion that, among the factors affecting the tourists aspiring to travel to Iran and consequently upon the foreign exchange revenue earned, the variable of "insecurity and domestic upheavals" is more significant than all other variables. This, the hypothesis, can be said to have been verified by the arguments given. 
Many factors such as socio-political and cultural conditions exert some degree of impact on feeling of security. The feeling of security is, however, a qualitative issue, and there is no index to measure it precisely. The feeling of insecurity that is created by social conditions emerges both at the time of war and also during peacetime. In this article only the insecurity caused by the war and the revolution has been examined. The extent of the feeling of social insecurity which is totally dependent on the issues of social values which ought to be the subject of further study.

More efforts must be made to modify the social atmosphere in this regard and only after the present capacity to absorb tourists is saturated should new facilities be established. Of course, considering the historical position and extensive cultural heritage of the country, the possibilities for attracting international tourists outweighs the capacity of the present tourism facilities by many folds (Musai, 1999). Thus, since for now the deficiencies in the facilities and accommodations do not pose impediments for attracting international tourists, and the major hindrance is the variable of "feeling of insecurity", policy makers and officials should adopt appropriate policies to eliminate the feeling of insecurity. This has been the major factor that has served to impede the flow tens of billions of tourist dollars to the country. This objective is definitely feasible through adopting more enlightened cultural policies and allocating a small expenditure budget within a reasonable time.

\section{Acknowledgement}

This article is extracted from economics of culture project and the authors would like to acknowledge the financial of University of Tehran for this research under grant number 4460001/1/3-12.

\section{Corresponding Author}

Maysam Musai, Faculty of social Sciences, University of Tehran, Tehran, Iran Email: mousaaei@ut.ac.ir

\section{References}

Alvani, M, Z., Dehdashti.(1993) The Basics and Principles of Tourism, Tehran: Janbazan and Mostazafan Foundation.

Arbel, A., A. Revid.(1985) On Recreation Demand: A Time Series Approach 17: 979990.

Bakkal, I. , A.Scoperlouda,(1992) Characteristics of U.S. Demand for European Tourism: A Tornslog Approach. Weltwirtschattliches Archivis.

Diamond, J.(1971) Tourism's Role in Economic Development: The Cast Reexamined", Economic Development and Cultural Change, PP. 539-552.

Ershadi, A. (1996) The Budget for National Organizations and Tourism, Tehran: The Center for Political Studies and Research.

Fayz-Bakhsh, H. (1997) The Conditions of International Tourism in Iran and the World. Tehran: School of Tourism Services and Information.

Fujii, E., M. Khaled, J. Mak.(1985) An Almost Ideal Demand System for Visitor Expenditures. Journal of Transport Economics and Policy PP. 161-171. 
Kliman, M.L.(1981) A Quntitative Analysis of Canadian Overseas Tourism. Canadian Overseas Tourism Transportation Research, 15A- 6: 487-497.

Lancaster,(1966) A New Approach to Consumer Theory, Journal of Political Economy. 74:132-157.

Musai, M. (2000) The Economy Of Tourism And The Cultural Heritage In Iran. Tehran: Center For Statistics, and planning Of The Art And Cultural Studies.

Peeran, P. (1994) An introduction to planning for Tourism. The Journal for Political and economic information N0s. 45-46.

Quanddt, R.(1970) The Demand for Travel: Theory and Measurement. Lexington: Health Lexington Books.

Rogg, D.(1973) The Choice of Journey Destination: A Theoretical and Empirical Analysis. Review of Economics and Statistics 55(1):64-72.

Sakai, M. (1988) Micro Analysis of Business Travel Demand, Applied Economics, Vol. 20:Q41-1495.

Center For Applied Research,(1994) Sociology And Tourism. Tehran: Center For Applied Research.

Sabagh-e Kermani, A. (1994) A Survey of Tourism Circumstances and an Estimation of Distribution of Demand and Supply of International Tourism in Iran. Tehran: Center for Fundamental Research.

Truett, D., L.Truett.(1987) The Response of Tourism to International Economic Conditions: Greece, Mexico and Spain. pp.177-189.

Uysal, M., J. Crompton.(1984) Determinations of Demand for International Tourist Flows to Turkey. Tourism Management Dec: 288-297.

Van Derkinjff , J. Ootehaver.(1990) Optimizing Tourist Policy: A Linear Programing Approach Reginal Studies, 24:55-64.

Witt, S. (1980) An Abstract Model of Foreign Holiday Demand. Applied Economics 42:163-180. 
$\mathrm{i}-\mathrm{h}=(1-\mathrm{d} / 2) \sqrt{\frac{n}{1-n \cdot \operatorname{var}(z 8)}}$ 